\title{
Análise jurídica do artigo 196 da Constituição Federal de 1988, à luz da jurisprudência do Supremo Tribunal Federal
}

Legal scrutiny of Article 196 of the Brazilian Constitution, in the light of the Supreme Court jurisprudence

\section{Tiago Souza Nogueira de Abreu}

Advogado. Especialista em Direito Sanitário. Juiz de Direito do Estado de Mato Grosso. Cuiabá, MT

Resumo: $O$ artigo analisa 0 atual entendimento do Supremo Tribunal Federal brasileiro acerca do direito a saúde, a partir da interpretação do artigo 196 da Constituição Federal de 1988, consoante as decisões proferidas no período de março de 2010 a junho de 2011. Destaca-se o entendimento daquela Corte de que a responsabilidade em garantir o acesso a saúde é partilhada e solidária entre os entes que compõe a federação; que o caráter programático da referida disposição constitucional não afasta o dever do ente federado de fornecer os meios necessários para o gozo do direito à saúde; e que cabe ao Poder Judiciário, quando acionado, determinar a pronta e eficaz prestação do serviço público de acesso à saúde ao cidadão que tem o seu direito negado. O Supremo Tribunal Federal tem o entendimento consolidado no sentido de que o conteúdo jurídico do artigo 196 da Constituição Federal irradia seus efeitos de forma plena, estabelecendo um vínculo jurídico cogente ao Estado quando demandado na temática da saúde, não importando, nesse particular, qual dos entes federados figure no polo passivo, já que a responsabilidade pela prestação do serviço é partilhada e solidária.

Palavras-chave: Direito à saúde; responsabilidade do Estado; Supremo Tribunal Federal (Brasil), jurisprudência.

Resumen: El artículo examina la comprensión de la Corte Suprema Federal de Brasil sobre el derecho a la salud, a partir de la interpretación del artículo 196 de la Constitución Federal de 1988, en función de las decisiones adoptadas en el período marzo 2010 a junio 2011. Se destaca la comprensión de la Corte de que: la responsabilidad de garantizar el acceso a la atención à la salud es compartida y solidaria entre los entes de la federación; el carácter programático de esa disposición constitucional no elimina la obligación del ente federado para proporcionar los servicios necesarios para el disfrute del derecho a la salud; corresponde al Poder Judicial, cuando demandado, determinar la prestación rápida y eficaz de los servicios públicos de acceso a la asistencia a la salud a los ciudadanos que tienen sus derechos negados. El Tribunal Supremo ha consolidado la comprensión de que el contenido jurídico del artículo 196 de la Constitución Federal irradia sus efectos plenamente, estableciendo un vínculo jurídico coercible al Estado, cuando demandado en el tema de la salud, y no importa, en este particular, cuál de los entes de la Federación aparece como parte demandada, ya que la responsabilidad de la prestación del servicio es compartido y solidaria entre todos.

Palabras clave: Derecho a la Salud; responsabilidad del Estado, federación; Supremo Tribunal Federal (Brasil), jurisprudencia. 
Abstract: The paper analyzes the current understanding of the Brazilian Federal Supreme Court on the right to health, from the interpretation of Article 196 of the Constitution of 1988, according to the decisions taken in the period March 2010 to June 2011. Stands out the understanding of that Court that: the responsibility for ensuring access to health care is shared and solidary among the entities of the Federation; the programmatic nature of that constitutional provision does not remove the duty of the federated entity to provide the necessary facilities for the enjoyment of the right to health; and that it is up to the Judiciary, when actuated, to determine the prompt and effective public service provision of access to healthcare to citizens who have their rights denied. The Brazilian Supreme Court has consolidated the understanding that the legal content of the article 196 of the Federal Constitution radiates its effects fully, establishing a cogent juridical relationship when the State is sued on the issue of health, no matter, in this particular, which of the federated entity appearing in defendant, since the responsibility for providing the service is shared and solidary between all of them.

Keywords: Right to Health; State responsibility; Federal Supreme Court (Brazil), jurisprudence.

\section{Introdução}

Com a promulgação da Constituição Federal de 1988, o tema da saúde passou a ter uma dimensão jurídica e constitucional de maior envergadura, já que foi expressamente declarado no corpo do seu texto o direito à saúde, impondo ao Estado o dever de assegurar, mediante políticas sociais e econômicas, o acesso universal e igualitário da população brasileira aos serviços públicos de promoção, proteção e recuperação da saúde.

Até 1988, o sistema público de saúde brasileiro não tinha um tratamento constitucional específico, o Estado apenas garantia o atendimento médico aos indivíduos que possuíssem carteira de trabalho assinada e estivessem em dia com os seus recolhimentos a Previdência Social. Ou seja, aqueles que não estivessem no mercado formal, que era a maioria da população, ou ficavam excluídos do serviço público ou eram atendidos pelas Santas Casas de Misericórdia, e aqueles que tinham recursos pagavam pelos serviços privados.

Conforme salienta Marques.

(...) o papel do Estado, em relação à prestação em matéria de saúde, como um direito do trabalhador assalariado, resumia-se à prestação de assistência médica e restringia-se basicamente ao gerenciamento da compra e oferta dos serviços privados de saúde aos beneficiários públicos. Percebe-se, dessa forma, que no Brasil a proteção jurídica a saúde de todos, independente de quaisquer requisitos como renda e inserção no mercado de trabalho, era inexistente. Os cidadãos não tinham direito de receber qualquer assistência médica ou sanitária do 
Estado, a menos que preenchessem os requisitos necessários (Marques, 2009, p. 67-68).

Em função da ausência da efetiva prestação dos serviços de saúde pública à população brasileira, o óbvio ocorreu, ou seja, o país mergulhou numa verdadeira crise na área da saúde nas décadas de 1970 e 1980, tendo então começado a surgir movimentos de profissionais de saúde, universitários, políticos, intelectuais preocupados com a situação, configurando-se o que ficou conhecido como Movimento da Reforma Sanitária.

Pode-se afirmar que, no Brasil, a reforma sanitária foi associada à ideia de movimento e movimento, como se sabe, significa processo, fenômeno dinâmico e inacabado. O lapso temporal que marcou o início da dinamização do processo reformista foi em meados de 1970, podendo se destacar a criação, dentre outras instituições, do Centro Brasileiro de Estudos de Saúde (CEBES) e da Associação Brasileira de Pós- Graduação em Saúde Coletiva (ABRASCO) (Cohn, 1989).

Com o objetivo de ampliar o debate da saúde pública no âmbito da sociedade, essas instituições fomentavam a discussão acerca do tema trazendo ideias e ideais com intuito de construir uma nova perspectiva sobre o processo saúde-doença, prevenção-cura, prática médica, planejamento e formação de recursos humanos até então vigentes (Silva, 2011).

No ano de 1986, o Presidente da República convocou a VIII Conferência Nacional de Saúde, momento oportuno em que foram discutidas premissas acerca da criação de um novo sistema de saúde e dos princípios da universalidade, da integralidade e da equidade, que abrangeriam o Sistema Único de Saúde (SUS), bem como foram lançadas as premissas que positivaram o direito à saúde na Constituição da República Federativa de 1988 (Conasems, 2007).

Fica claro, portanto, que o movimento sanitário fomentou o debate e lançou os fundamentos que vieram a construir um novo sistema de saúde pública no país, destacando-se que, pela primeira vez na história republicana brasileira, foi positivado na Carta Política um capítulo específico sobre o direito à saúde, dotando-o de eficácia capaz de obrigar o Estado a garantir o acesso universal, equânime e integral a saúde a todos os brasileiros.

A Carta Cidadã de 1988, em seu Capítulo II, "Dos Direitos Sociais", traz no artigo 6ำ (redação dada pela Emenda Constitucional 64/2010) um comando que 
ratifica a toda população a existência plena de direitos, em um manto imbuído de coercitividade e íntegra observância, destacando-se, dentre os demais direitos, o direito a saúde:

Art. 6․․ São direitos sociais a educação, a saúde, a alimentação, o trabalho, a moradia, o lazer, a segurança, a previdência social, a proteção à maternidade e à infância, a assistência aos desamparados, na forma desta Constituição.

A propósito, ensina Vilas Boas:

(...) a saúde é prioridade de qualquer plano de Governo nas mesmas proporções da educação, em todos os seus níveis. O Sistema Único de Saúde - SUS, viabilizado pela Lei n. 8.080, de 19 de setembro de 1990, teve por primeira disposição geral, o primado da saúde como direito fundamental do ser humano, cabendo ao Estado prover as condições indispensáveis ao seu pleno exercício (Vilas Boas, 2011, p. 77).

A Lei $n^{\circ}$ 8.080, de 1990, que institucionalizou o SUS à luz dessa concepção ampla do conceito saúde adotada na Constituição, reafirma em seu artigo $3^{\circ}$ que, entre outros, a alimentação, a moradia, o saneamento básico, o meio ambiente, o trabalho, a renda, a educação, o transporte, o lazer determinam significativamente os níveis de saúde da população, e esses, por sua vez, expressam a organização social e econômica do País (Brasil, 1990).

Fica patente, portanto, que os direitos sociais (art. 6ํㅜ 11 da Constituição da República Federativa do Brasil de 1988) fazem parte de uma instrumentalidade ligada às liberdades positivas, que obriga o chamado Estado Social de Direito a analisar todas as nuances legais que interligam a este instituto pátrio, tendo como escopo proporcionar a todos brasileiros e estrangeiros residentes no país, principalmente aos hipossuficientes, uma condição de vida em parâmetros devidamente aceitáveis e esperados (Paulo \& Alexandrino, 2010).

Em outras palavras, não é mais possível interpretar o direito à saúde como uma norma simplesmente programática, pois o comando constitucional contido no artigo 196 da Constituição Federal vigente, em leitura conjunta com o caput do artigo 6o, institui um dever correlato a um sujeito determinado: o Estado (União, Estado e Município) que, por isso, tem a obrigação de prestar o serviço de saúde a todos de forma gratuita, universal, equânime e integral.

O direito público subjetivo à saúde, além de representar um direito social, conforme já enfatizado, qualifica-se também como um direito fundamental que assiste a todos, sem distinção de raça, credo ou cor, haja vista a sua íntima 
vinculação ao direito à vida e ao princípio da dignidade da pessoa humana, bem como pela própria disposição constitucional do tema na Carta Política brasileira.

Nessa quadra, afirmar que o direito à saúde é um direito fundamental significa dizer que ele vincula os Poderes Públicos nas três esferas (Executivo, Legislativo e Judiciário), não podendo sequer ser extirpado da Constituição por meio de emenda constitucional.

É válido dizer, ainda, que o Estado, seja ele representado por qualquer um dos Poderes, ao desenvolver a sua atribuição deve, dentro dos limites da realidade social e financeira, fazer o possível para promover a saúde de forma a tornar factível o que a norma contém em ficção.

Neste contexto, deve o Poder Legislativo e Executivo, principalmente, porque são responsáveis em criar e executar as normas, respectivamente, dar a concreção máxima ao direito à saúde conforme consagrado na legislação constitucional e infralegal, e ao Judiciário, como o guardião da Constituição e das leis, corrigir, garantir e, em alguns casos, obrigar de forma coercitiva os demais poderes a darem à concreção necessária para a garantia da saúde.

A propósito, conforme preleciona Silva:

(...) mais do que a simples positivação dos direitos sociais - que traduz estágio necessário ao processo de sua afirmação constitucional e que atua como pressuposto indispensável à eficácia jurídica - recai sobre o Estado a obrigação de criar condições objetivas que possibilitem o efetivo acesso à saúde (Silva, 2000, p. 199).

Ainda sobre a necessária exequibilidade imediata dos direitos fundamentais do homem, vale refletir a crítica de Bobbio:

(...) já nos perguntamos alguma vez que gênero de normas são essas que não ordenam, proíbem ou permitem hic et nunc, mas ordenam, proíbem e permitem num futuro indefinido e sem um prazo de carência claramente delimitado? E, sobretudo, já nos perguntamos alguma vez que gênero de direitos são esses que tais normas definem? Um direito cujo reconhecimento e cuja efetiva proteção são adiados sine die, além de confiados à vontade de sujeitos cuja obrigação de executar o "programa" é apenas uma obrigação moral ou, no máximo, política, pode ainda ser chamado corretamente de "direito"? (Bobbio, 1992, p. 77/78)

Desse modo, não basta que o Estado reconheça formalmente 0 direito à saúde, faz-se necessário que promova todas as medidas políticas, sociais e econômicas para assegurar que esse direito seja integralmente respeitado e plenamente garantido, uma vez que a própria Constituição promete uma sociedade 
justa, fraterna, solidária, tendo como um de seus princípios basilares a dignidade da pessoa humana.

A fim de dar efetividade ao dispositivo constitucional que garante 0 acesso amplo e irrestrito à saúde (art. 196), impõe-se ao Estado a obrigação de formular e implementar políticas econômicas e sociais, com a finalidade de proporcionar melhoria nas condições de vida e saúde dos diversos grupos da população, e, por meio de propostas sistematizadas em planos, programas e projetos, assegurar o acesso universal e igualitário as ações e serviços de promoção, proteção e recuperação da saúde.

Nessa seara, extrai-se como princípios norteadores do Sistema de Saúde brasileiro, a universalidade, equidade e a integralidade.

A universalidade pode ser definida como um objetivo a ser alcançado, uma vez que a saúde é reconhecida como um direito do/para o ser humano, devendo o Estado garantir condições indispensáveis para o seu pleno exercício, para tanto, assevera Teixeira que:

(...) é preciso se desencadear um processo de universalização, isto é, um processo de extensão de cobertura dos serviços, de modo que venham, paulatinamente, a se tornar acessíveis a toda a população, sendo, portanto, necessário eliminar barreiras jurídicas, econômicas, culturais e sociais que se interpõem entre a população e os serviços (Teixeira, 2012, p. 3).

Por sua vez, o princípio da equidade traz, na sua gênese, a atribuição de diminuir as desigualdades, o que não significa tratar todos de maneira igual, mas atender as necessidades de cada um, levando em consideração as peculiaridades individuais e do grupo social, investindo onde a carência é maior.

Assim, segundo Teixeira (2012, p. 5), na saúde, especificadamente, as "desigualdades sociais se apresentam como desigualdades diante do adoecer e do morrer, reconhecendo-se a possibilidade de redução dessas desigualdades, de modo a garantir condições de vida e saúde mais iguais para todos".

Dessa forma, entende-se que o acesso igualitário à saúde de que trata o dispositivo constitucional, não deve ser visualizado apenas como uma forma de oferecer tratamento de saúde igualitário para todos, indistintamente, mas sim em assegurar condições de vida e saúde mais dignas, atendendo as necessidades e peculiaridades de cada indivíduo, considerando, sempre, o grupo social no qual está inserido. 
No tocante a integralidade, embora muito se discuta sobre o seu alcance, Teixeira, assevera:

A noção de integralidade diz respeito ao leque de ações possíveis para a promoção da saúde, prevenção de riscos e agravos e assistência a doentes, implicando a sistematização do conjunto de práticas que vem sendo desenvolvidas para o enfrentamento dos problemas e 0 atendimento das necessidades de saúde. A integralidade é (ou não), um atributo do modelo de atenção, entendendo-se que um "modelo de atenção integral à saúde" contempla o conjunto de ações de promoção da saúde, prevenção de riscos e agravos, assistência e recuperação. Um modelo "integral", portanto, é aquele que dispõe de estabelecimentos, unidades de prestação de serviços, pessoal capacitado e recursos necessários, à produção de ações de saúde que vão desde as ações inespecíficas de promoção da saúde em grupos populacionais definidos, às ações específicas de vigilância ambiental, sanitária e epidemiológica dirigidas ao controle de riscos e danos, até ações de assistência e recuperação de indivíduos enfermos, sejam ações para a detecção precoce de doenças, sejam ações de diagnóstico, tratamento e reabilitação (Teixeira, 2012, p. 6).

Desse modo, pode-se extrair que a integralidade diz respeito à organização, que tem como objetivo oferecer a todos, independente das condições econômicas, da idade, da habitação entre outras peculiaridades, ações e serviços para a promoção da saúde, prevenção de doenças, e o seu tratamento.

\section{Metodologia}

Realizamos pesquisa descritiva documental com coleta das decisões do Supremo Tribunal Federal, proferidas no período de março de 2010 a junho de 2011, com demandas em que tivesse envolvido o tema saúde, destacando a forma como vem sendo interpretado pela Corte o artigo 196 da CF/88. O objetivo é conhecer o alcance e as implicações provenientes dessas decisões no âmbito dos entes federados, União, estados e municípios.

Os dados foram obtidos a partir de consulta ao portal do STF, no link “jurisprudência”, cujo banco de dados é de acesso público.

Utilizaram-se como argumentos de busca o artigo 196 da CF/88 e a palavra "saúde", tendo sido encontrados 45 acórdãos, dos quais foram selecionados 7 , julgados no período de março de 2010 a junho de 2011, envolvendo o tema acesso universal e igualitário da população brasileira aos serviços públicos de promoção, proteção e recuperação da saúde. 
Os demais acórdãos foram desconsiderados por não atenderam ao critério de pertinência temática adotado, isto é, por utilizarem a interpretação do artigo 196 da CF apenas como subsidio para outro tema de maior relevância, o que foge do escopo do estudo.

As informações obtidas foram analisadas qualitativamente e expostas por meio de um quadro.

\section{Resultados e discussão}

Feita uma breve análise acerca do conteúdo jurídico do artigo 196 da CF, pretende-se, nesse tópico, trazer a lume as decisões proferidas pela Corte Constitucional brasileira no período de março de 2011 a junho de 2011, destacando o entendimento esposado pelos Ministros acerca do tema saúde, quando submetido o recurso a julgamento nos diversos casos concretos que assolam as varas judiciais espalhadas por todo o território brasileiro. (Quadro 1)

Conforme se extrai dos sete julgados destacados, a Corte Constitucional brasileira decidiu, em todos os casos, que a responsabilidade em garantir o acesso a saúde é partilhada e solidária entre os entes que compõe a federação. A União, os estados e os municípios são responsáveis em conferir efetividade ao comando constitucional, com o fim de implementar as medidas necessárias para proteção e recuperação da saúde dos cidadãos.

Observa-se ainda, que o caráter programático do artigo 196 da CF/88 não afasta o dever do ente federado de fornecer os meios necessários para o gozo do direito à saúde, cabendo ao Poder Judiciário, quando acionado, determinar a pronta e eficaz prestação do serviço público de acesso à saúde ao cidadão que tem o seu direito negado.

Com efeito, percebe-se, de forma bastante clara, que o Supremo Tribunal Federal tem o entendimento consolidado no sentido de que o conteúdo jurídico do artigo 196 da Constituição Federal irradia seus efeitos de forma plena, estabelecendo um vínculo jurídico cogente ao Estado quando demandado na temática da saúde, não importando, nesse particular, qual dos entes federados figure no pólo passivo, já que a responsabilidade pela prestação do serviço é partilhada e solidária. 
Quadro 1 - Acórdãos proferidos pelo STF no período de março de 2010 a junho de 2011.

\begin{tabular}{|c|c|}
\hline Decisão & Ideia central \\
\hline $\begin{array}{l}\text { Ementa: Agravo de instrumento. Município. Cirurgia. Direito à saúde. } \\
\text { Agravo regimental desprovido. O recurso extraordinário, ao alegar que o } \\
\text { acórdão recorrido ofende o preceito do art. 198, versa questão } \\
\text { constitucional não ventilada na decisão recorrida e que não foi objeto de } \\
\text { embargos de declaração, faltando-lhe, pois, o indispensável } \\
\text { prequestionamento (Súmulas } 282 \text { e } 356 \text { ). O acórdão impugnado, ao } \\
\text { garantir o acesso da agravada, pessoa de insuficientes recursos } \\
\text { financeiros, a tratamento médico condigno ao quadro clínico } \\
\text { apresentado, resguardando-lhe o direito à saúde, decidiu em } \\
\text { consonância com a jurisprudência desta Corte sobre o tema. } \\
\text { Precedentes. Consolidou-se a jurisprudência desta Corte no sentido de } \\
\text { que, embora o art. } 196 \text { da Constituição de } 1988 \text { traga norma de caráter } \\
\text { programático, o Município não pode furtar-se do dever de propiciar os } \\
\text { meios necessários ao gozo do direito à saúde por todos os cidadãos. Se } \\
\text { uma pessoa necessita, para garantir o seu direito à saúde, de } \\
\text { tratamento médico adequado, é dever solidário da União, do estado e } \\
\text { do município providenciá-lo. Precedentes. Agravo regimental } \\
\text { desprovido. (Al 550530 AgR, Relator: Min. Joaquim Barbosa, Segunda } \\
\text { Turma, julgado em } 26 / 06 / 2012 \text {, Acórdão eletrônico DJe-161 Divulg 15- } \\
08-2012 \text { Public } 16-08-2012 \text { ). }\end{array}$ & $\begin{array}{l}\text { O caráter programático } \\
\text { do art. } 196 \text { da } \\
\text { Constituição Federal } \\
\text { (1988), não afasta dever } \\
\text { do Município em } \\
\text { fornecer os meio meios } \\
\text { necessários para o gozo } \\
\text { do direito à saúde. }\end{array}$ \\
\hline $\begin{array}{l}\text { Ementa: Saúde - promoção - medicamentos. O preceito do artigo } 196 \\
\text { da Constituição Federal assegura aos necessitados o fornecimento, } \\
\text { pelo Estado, dos medicamentos indispensáveis ao restabelecimento da } \\
\text { saúde. (ARE } 650359 \text { AgR, Relator: Min. Marco Aurélio, Primeira Turma, } \\
\text { julgado em 07/02/2012, Acórdão eletrônico DJe-051 Divulg 09-03-2012 } \\
\text { Public 12-03-2012). }\end{array}$ & $\begin{array}{l}\text { Saúde é direito de } \\
\text { todos e dever do Estado } \\
\text { e deve ser garantido } \\
\text { pelo Estado. }\end{array}$ \\
\hline $\begin{array}{l}\text { Ementa: Agravo regimental no recurso extraordinário. Constitucional e } \\
\text { Processual Civil. Direito à saúde (Art. 196, CF). Fornecimento de } \\
\text { medicamentos. Solidariedade passiva entre os entes federativos. } \\
\text { Chamamento ao processo. Deslocamento do feito para Justiça Federal. } \\
\text { Medida protelatória. Impossibilidade. } 1 \text {. O artigo } 196 \text { da CF impõe o } \\
\text { dever estatal de implementação das políticas públicas, no sentido de } \\
\text { conferir efetividade ao acesso da população à redução dos riscos de } \\
\text { doenças e às medidas necessárias para proteção e recuperação dos } \\
\text { cidadãos. 2. O Estado deve criar meios para prover serviços médico- } \\
\text { hospitalares e fornecimento de medicamentos, além da implementação } \\
\text { de políticas públicas preventivas, mercê de os entes federativos } \\
\text { garantirem recursos em seus orçamentos para implementação das } \\
\text { mesmas. (arts. 23, II, e 198, § 10́, da CF). 3. O recebimento de } \\
\text { medicamentos pelo Estado é direito fundamental, podendo o requerente } \\
\text { pleiteá-los de qualquer um dos entes federativos, desde que } \\
\text { demonstrada sua necessidade e a impossibilidade de custeá-los com } \\
\text { recursos próprios. Isto por que, uma vez satisfeitos tais requisitos, o } \\
\text { ente federativo deve se pautar no espírito de solidariedade para conferir } \\
\text { efetividade ao direito garantido pela Constituição, e não criar entraves } \\
\text { jurídicos para postergar a devida prestação jurisdicional. } 4 \text {. In casu, o } \\
\text { chamamento ao processo da União pelo Estado de Santa Catarina } \\
\text { revela-se medida meramente protelatória que não traz nenhuma } \\
\text { utilidade ao processo, além de atrasar a resolução do feito, revelando- } \\
\text { se meio inconstitucional para evitar o acesso aos remédios necessários } \\
\text { para o restabelecimento da saúde da recorrida. } 5 \text {. Agravo regimental no } \\
\text { recurso extraordinário desprovido. (RE } 607381 \text { AgR, Relator: Min. Luiz } \\
\text { Fux, Primeira Turma, julgado em } 31 / 05 / 2011 \text {, DJe-116 Divulg } 16-06- \\
2011 \text { Public } 17-06-2011 \text { Ement vol-02546-01 PP-00209 RTJ vol-00218- } \\
\text { PP-00589) }\end{array}$ & $\begin{array}{l}\text { O art. } 196 \text { da } \\
\text { Constituição Federal } \\
\text { (1988), impõe o dever } \\
\text { estatal de } \\
\text { implementação das } \\
\text { políticas públicas, no } \\
\text { sentido de dar } \\
\text { efetividade ao acesso à } \\
\text { população à redução de } \\
\text { riscos de doenças e às } \\
\text { medidas necessárias } \\
\text { para a proteção e } \\
\text { recuperação dos } \\
\text { cidadãos. }\end{array}$ \\
\hline
\end{tabular}




\begin{tabular}{|c|c|}
\hline Decisão & Ideia central \\
\hline $\begin{array}{l}\text { Ementa: Direito Constitucional. Direito à Saúde. Agravo regimental em } \\
\text { agravo de instrumento. Implementação de políticas públicas. Ação civil } \\
\text { pública. Prosseguimento de julgamento. Ausência de ingerência no } \\
\text { poder discricionário do Poder Executivo. Artigos } 2^{\circ}, 6^{\circ} \text { e } 196 \text { da } \\
\text { Constituição Federal. } 1 \text {. O direito a saúde é prerrogativa constitucional } \\
\text { indisponível, garantido mediante a implementação de políticas públicas, } \\
\text { impondo ao Estado a obrigação de criar condições objetivas que } \\
\text { possibilitem o efetivo acesso a tal serviço. } 2 \text {. É possível ao Poder } \\
\text { Judiciário determinar a implementação pelo Estado, quando } \\
\text { inadimplente, de políticas públicas constitucionalmente previstas, sem } \\
\text { que haja ingerência em questão que envolve o poder discricionário do } \\
\text { Poder Executivo. Precedentes. 3. Agravo regimental improvido. (Al } \\
\text { 734487 AgR, Relatora: Min. Ellen Gracie, Segunda Turma, julgado em } \\
03 / 08 / 2010 \text {, DJe-154 Divulg 19-08-2010 Public 20-08-2010 Ement vol- } \\
02411-06 \text { PP-01220 RT v. 99, n. 902, 2010, p. 158-162) }\end{array}$ & $\begin{array}{l}\text { O direito a saúde é } \\
\text { prerrogativa } \\
\text { constitucional } \\
\text { indisponível, garantido } \\
\text { mediante a } \\
\text { implementação de } \\
\text { políticas públicas, } \\
\text { impondo ao Estado a } \\
\text { obrigação de criar } \\
\text { condições objetivas que } \\
\text { possibilitem o efetivo } \\
\text { acesso a tal serviço. }\end{array}$ \\
\hline $\begin{array}{l}\text { Ementa: Suspensão de Liminar. Agravo Regimental. Saúde pública. } \\
\text { Direitos fundamentais sociais. Art. } 196 \text { da Constituição. Audiência } \\
\text { Pública. Sistema Único de Saúde - SUS. Políticas públicas. } \\
\text { Judicialização do direito à saúde. Separação de poderes. Parâmetros } \\
\text { para solução judicial dos casos concretos que envolvem direito à saúde. } \\
\text { Responsabilidade solidária dos entes da Federação em matéria de } \\
\text { saúde. Ordem de regularização dos serviços prestados em hospital } \\
\text { público. Não comprovação de grave lesão à ordem, à economia, à } \\
\text { saúde e à segurança pública. Possibilidade de ocorrência de dano } \\
\text { inverso. Agravo regimental a que se nega provimento. (SL } 47 \text { AgR, } \\
\text { Relator: Min. Gilmar Mendes (Presidente), Tribunal Pleno, julgado em } \\
\text { 17/03/2010, DJe-076 Divulg 29-04-2010 Public 30-04-2010 Ement vol- } \\
\text { 02399-01 PP-00001) }\end{array}$ & $\begin{array}{l}\text { Parâmetros para } \\
\text { solução judicial dos } \\
\text { casos concretos que } \\
\text { envolvem direito à } \\
\text { saúde. } \\
\text { Responsabilidade } \\
\text { solidária dos entes da } \\
\text { Federação em matéria } \\
\text { de saúde. }\end{array}$ \\
\hline $\begin{array}{l}\text { Ementa: Suspensão de Segurança. Agravo Regimental. Saúde pública. } \\
\text { Direitos fundamentais sociais. Art. } 196 \text { da Constituição. Audiência } \\
\text { Pública. Sistema Único de Saúde - SUS. Políticas públicas. } \\
\text { Judicialização do direito à saúde. Separação de poderes. Parâmetros } \\
\text { para solução judicial dos casos concretos que envolvem direito à saúde. } \\
\text { Responsabilidade solidária dos entes da Federação em matéria de } \\
\text { saúde. Fornecimento de medicamento: Zavesca (miglustat). Fármaco } \\
\text { registrado na Anvisa. Não comprovação de grave lesão à ordem, à } \\
\text { economia, à saúde e à segurança públicas. Possibilidade de ocorrência } \\
\text { de dano inverso. Agravo regimental a que se nega provimento. } \\
\text { (STA } 175 \text { AgR, Relator: Min. Gilmar Mendes (Presidente), Tribunal } \\
\text { Pleno, julgado em 17/03/2010, DJe-076 Divulg 29-04-2010 Public 30- } \\
\text { 04-2010 Ement vol-02399-01 PP-00070) }\end{array}$ & $\begin{array}{l}\text { Parâmetros para } \\
\text { solução judicial dos } \\
\text { casos concretos que } \\
\text { envolvem direito à } \\
\text { saúde. } \\
\text { Responsabilidade } \\
\text { solidária dos entes da } \\
\text { Federação em matéria } \\
\text { de saúde. }\end{array}$ \\
\hline
\end{tabular}

Fonte: STF. Disponível em: http://www.stf.jus.br/portal/jurisprudencia/pesquisarJurisprudencia.asp. Acesso em: 5 dez. 2011.

\section{Conclusão}

A força normativa da Constituição exige que se compreenda o direito à saúde dele se extraindo os maiores efeitos possíveis, de modo a evitar qualquer tipo de exteriorização de ações, seja ela emanada por qualquer um dos Poderes (Executivo, Legislativo ou Judiciário) que implique em restrição à irradiação dos seus comandos como consagrados no texto magno, ainda que a norma objetive uma perspectiva utópica. 
É indispensável que se compreenda a saúde não apenas sob o enfoque coletivo, mas, sobretudo, pelo seu indissociável valor individual, já que está em jogo, quando se trata deste tema, o fundamento que alicerça todos os demais direitos - a vida. Para isso, é necessário ter uma lúcida interpretação e aplicação da norma quando enfrentado o caso concreto.

Nesse sentido, a Corte Constitucional Brasileira tem demonstrado ao longo dos anos, e mais especificamente nos julgados estudados, uma disposição em interpretar a norma positivada (art. 196, CF), quando sob julgamento tema envolvendo saúde, de maneira a minimizar o seu aspecto formal (programático), dotando-a de eficácia plena, de modo a garantir que o bem da vida perquirido no caso concreto seja sempre pronta e integralmente atendido pelos demais Poderes.

\section{Referências}

BOBBIO, Norberto. A era dos direitos. Tradução: Carlos Nelson Coutinho. Rio de Janeiro: Campus, 1992. ISBN 85-7001-710-3

BOAS, Marco Antonio Vilas. Estatuto do Idoso Comentado. (3 ed.) Rio de Janeiro: Forense, 2011. ISBN 9788530936174

BRASIL. Conselho Nacional de Secretários Municipais de Saúde. Movimento Sanitário Brasileiro na Década de 70: a participação das universidades e dos municípios, Brasília: CONASEMS, 2007. ISBN 978-85-89545-08-2

. Constituição (1988). Constituição da República Federativa do Brasil. Brasília: Senado Federal, 1988. ISBN 978-85-7018-354-5

. Ministério da Saúde. Secretaria executiva. Sistema Único de Saúde (SUS): princípios e conquistas. Brasília: Ministério Público, 2000. ISBN 85-334-0325-9

. Lei $n^{\circ}$ 8.080, de 19 de setembro de 1990. Dispõe sobre as condições para a promoção, proteção e recuperação da saúde, a organização e o funcionamento dos serviços correspondentes e dá outras providências. Diário Oficial da União, 20 set. 1990. Disponível em: http://www.planalto.gov.br/ccivil 03/Leis/L8080.htm (Acessado em 5 dez. 2012).

Supremo Tribunal Federal. [on line] Disponível em: http://www.stf.jus.br/portal/jurisprudencia/pesquisarJurisprudencia.asp $\quad$ (Acessado em 5 dez. 2012).

COHN, Amélia. Caminhos da Reforma Sanitária. Lua Nova, São Paulo, 19, 1989. ISSN 0102-6445

MARQUES, Silvia Badim. Revista de Direito Sanitário, 10(2):64-86, jul./out. 2009. ISSN 2316-9044

PAULO, Vicente; ALEXANDRINO, Marcelo. Resumo de Direito Constitucional Descomplicado. (3 ed.) Rio de Janeiro: Forense; São Paulo: Método, 2010. ISBN 9788530932770 
SILVA, Alessandra Ximenes da. A Reforma Sanitária Brasileira em Debate. [on line] Disponível em: http://www.joinpp.ufma.br/ (Acessado em 23 out. 2012).

SILVA, Jose Afonso da. Poder Constituinte e Poder Popular, São Paulo: Malheiros, 2000. ISBN 8574201529

TEIXEIRA, Carmem. Os Princípios do Sistema Único de Saúde. [on line] Disponível em: http://www.saude.ba.gov.br/pdf/OS PRINCIPIOS DO SUS.pdf (Acessado em 24 out. 2012). 